\title{
Collagen-grafted porous HDPE/PEAA scaffolds for bone reconstruction
}

\author{
Chang-Shik Kim', Kyung-Hye Jung ${ }^{2}$, Hun Kim ${ }^{3}$ Chan-Bong Kim³ and Inn-Kyu Kang ${ }^{1 *}$
}

\begin{abstract}
After tumor resection, bone reconstruction such as skull base reconstruction using interconnected porous structure is absolutely necessary. In this study, porous scaffolds for bone reconstruction were prepared using heat-pressing and salt-leaching methods.

High-density polyethylene (HDPE) and poly(ethylene-co-acrylic acid) (PEAA) were chosen as the polymer composites for producing a porous scaffold of high mechanical strength and having high reactivity with biomaterials such as collagen, respectively. The porous structure was observed through surface images, and its intrusion volume and porosity were measured. Owing to the carboxylic acids on PEAA, collagen was successfully grafted onto the porous HDPE/PEAA scaffold, which was confirmed by FT-IR spectroscopy and electron spectroscopy for chemical analysis. Osteoblasts were cultured on the collagen-grafted porous scaffold, and their adhesion, proliferation, and differentiation were investigated. The high viability and growth of the osteoblasts suggest that the collagen-grafted porous HDPE/PEAA is a promising scaffold material for bone generation.
\end{abstract}

Keywords: High-density polyethylene, Porous scaffolds, Collagen, Osteoblasts, Differentiation

\section{Background}

For bone reconstruction such as skull base reconstruction after tumor resection, an interconnected porous structure is critical to mimicking the bone extracellular matrix [1-8]. The pore size, porosity, and pore interconnectivity of porous bone scaffolds determine their performance in functions such as cell attachment and nutrient diffusion, which enhances soft tissue and bone ingrowth and eventually resistance to infection or deformation. Moreover, mechanical stability is mandatory for the mechanical support that is required during the repair and regeneration of damaged or degenerated bone $[7,9]$. Porous scaffolds for biomedical applications have been successfully fabricated via the sol-gel process [10], salt-leaching method [8, 11-13], electrospinning [14-17], and microsphere-sintering technique [18, 19]. However, the lack of mechanical strength of the porous materials can cause instability of the pore structures and hence limit their biomedical applications, and thus the choice of scaffold material is crucial.

\footnotetext{
* Correspondence: ikkang@knu.ac.kr

${ }^{1}$ Department of Polymer Science and Engineering, Kyungpook National

University, Daegu 702-701, South Korea

Full list of author information is available at the end of the article
}

The performance of porous scaffolds can be optimized by controlling their surface chemistry, because the interface between the porous scaffolds and cells determines the cellular behavior, such as cell adhesion, spreading, and proliferation [6]. Collagen is the main organic component of bones, and is hence a promising candidate material for the surface modification of porous scaffolds by promoting cell attachment and chemotactic responses [20].

High-density polyethylene (HDPE) shows excellent mechanical properties, and it has been widely used as an implant material for bone reconstruction [18, 21, 22]. Medpor $^{\circ}$ (Porex Technologies Co., USA) is one such porous HDPE scaffold for bone tissue engineering, used as an alloplastic material for craniofacial reconstruction [23, 24]. However, HDPE is inert and hydrophobic, and exhibits poor reactivity with biomaterials such as collagen. Several efforts have been made to improve the reactivity of PE for biomedical applications. The grafting of acrylic acid onto the PE film was conducted to improve protein immobilization and cell seeding [25]. It was also reported that plasma treatment effectively provides HDPE with a hydrophilic surface, which results in better reactivity with bioactive molecules [26]. The carboxylic acid groups of poly(ethylene-co-acrylic acid) 
(PEAA) make it an outstanding candidate to support the reactivity with collagen. Besides this, PEAA is mechanically stable, owing to the strong hydrogen bonds in its carboxylic acid groups, which can be effective crosslinkers between polymer chains.

In this study, the composite of HDPE and PEAA was chosen as scaffold material for cranial reconstruction owing to the high mechanical stability of HDPE and the high reactivity of PEAA with collagen. Before collagen grafting, the porous structure was prepared using a saltleaching method, which can provide the proper pore size and high porosity. Osteoblast cells were then cultured on the collagen-grafted porous HDPE/PEAA scaffold, and the cell adhesion, proliferation, and differentiation were measured to investigate their bone tissue compatibility. Porous scaffolds of HDPE and HDPE/PEAA without collagen grafting were also fabricated and studied as controls.

\section{Methods}

\section{Fabrication of collagen-grafted porous scaffolds}

Porous HDPE/PEAA scaffolds were fabricated by using a salt-leaching method $^{10}$. HDPE (Mw 85,000, Mn 13,500; Korea Petrochemical Industrial Co., Korea) and PEAA (acrylic acid $20 \mathrm{wt} \%$; Sigma-Aldrich Co., USA) beads $(\mathrm{w} / \mathrm{w}=3: 1)$ were mixed with sodium chloride (HDPE/PEAA: $\mathrm{NaCl}=1: 9$ ) with a particle size of 200$500 \mu \mathrm{m}$, using a melt mixing machine (Brabender, PlastiCorder Co.) at $160{ }^{\circ} \mathrm{C}$. Then, the mixture was cast in a circular mold (diameter $13 \mathrm{~mm}$, thickness $1.3 \mathrm{~mm}$ ) using a heat press machine (Yoochang Co., Korea). The resulting $\mathrm{HDPE} / \mathrm{PEAA} / \mathrm{NaCl}$ composite was immersed in distilled water to leach out the $\mathrm{NaCl}$, leaving pores in the composite. The salt-free porous HDPE/PEAA was washed with distilled water and air dried.

For obtaining high reactivity between the scaffold and collagen, L-lysine was grafted onto the scaffold surface to improve the affinity of the carboxyl groups to the amine groups in collagen. Before the L-lysine grafting, the carboxylic groups on the HDPE/PEAA scaffold were activated by immersing the scaffold into a 1-ethyl-3-(3dimethylaminopropyl) carbodiimide (0.25 wt\%; SigmaAldrich Co., USA) and N-hydroxysuccinimide (0.25 wt\%; Sigma-Aldrich Co., USA) aqueous solution for $6 \mathrm{~h}$ at room temperature. Afterwards, it was immersed in 3 wt\% L-lysine aqueous solution with gentle stirring. The carboxyl groups of L-lysine, attached to the scaffold surface, were also activated by this same method. Collagen-grafted HDPE/PEAA (HDPE/PEAA/Col) was produced by immersing the HDPE/PEAA scaffold in 3 wt\% collagen solution (in distilled water containing acetic acid, $\mathrm{pH} 4.3$ ) for $6 \mathrm{~h}$ with gentle stirring, and then it was washed with distilled water and dried.

\section{Characterization of the scaffolds}

The surface morphology of the porous HDPE, HDPE/ PEAA, and HDPE/PEAA/Col scaffolds was observed under a field emission scanning electron microscope (FE-SEM S4300; Hitachi, Japan) after sputter-coating with platinum. The chemical bonds and elemental composition were characterized by Fourier transform infrared (FT-IR; Mattson, Galaxy 7020A) spectroscopy and electron spectroscopy for chemical analysis (ESCA; ESCA LAB VIG microtech, Mt 500/1, and so forth, East Grinstead, UK), respectively.

Tensile properties were measured via a universal testing machine (Instron, model 4465) with a Zwick Roell tensile tester equipped with a $1 \mathrm{kgf}$ load cell, at $25{ }^{\circ} \mathrm{C}$ with an extension speed of $10 \mathrm{~mm} / \mathrm{min}$. The tensile strength and Young's modulus measure of each sample were calculated from the averages of 10 specimens.

The porosity of the porous scaffolds was determined by using a mercury intrusion porosimeter (AutoPore IV 9520; Micromeritics Co., USA). The advancing and retreating contact angles of mercury were taken to be $140^{\circ}$ and the surface tension was taken as $0.480 \mathrm{~N} / \mathrm{m}$ (480 dynes/cm).

\section{Cell behavior}

Cell behavior was observed by culturing osteoblast cells $\left(5 \times 10^{4}\right.$ cells $/ \mathrm{mL}$; MC3T3-E1, ATCC) on the scaffolds, at $37{ }^{\circ} \mathrm{C}$ in a humidified atmosphere with $5 \% \mathrm{CO}_{2}$, in Dulbecco's modified Eagle's medium (Gibco, USA) supplemented with $10 \%$ fetal bovine serum (Gibco, USA) and $1 \%$ penicillin G-streptomycin (Gibco, USA). After both 1 and 2 days of incubation, calcein-AM (1 mM in dimethyl sulfoxide) and propidium iodide (1.5 $\mathrm{mM}$ in distilled water) solutions were added and the scaffolds were left standing for $15 \mathrm{~min}$. The fluorescence images were visualized with a confocal laser scanning microscope (CLSM, Carl Zeiss, LSM 700, Germany).

To evaluate the cytoskeletal organization of cells on the porous scaffolds, double staining was performed. After 3 days of incubating the cell solution with the scaffold samples, the cells were fixed with $4 \%$ paraformaldehyde in PBS and permeabilized with $0.1 \%$ Triton X-100 in PBS for $15 \mathrm{~min}$. The samples were then incubated for $30 \mathrm{~min}$ in a PBS containing $1 \%$ bovine serum albumin, followed by the addition of tetramethylrhodamine-5isothiocyanate (TRITC)-conjugated phalloidin (Millipore, Cat. No. 90228). After $1 \mathrm{~h}$, the samples were incubated with 4,6-diamidino-2-phenylindole (DAPI) (Millipore, Cat. No. 90229) for $5 \mathrm{~min}$. The fluorescence images were taken with a confocal laser scanning microscope (CLSM 700).

The cell viability and proliferation on the porous scaffolds were evaluated using the 3-(4,5-dimethylthiazol-2yl)-2,5-diphenyltetrazolium bromide (MTT) assay and 


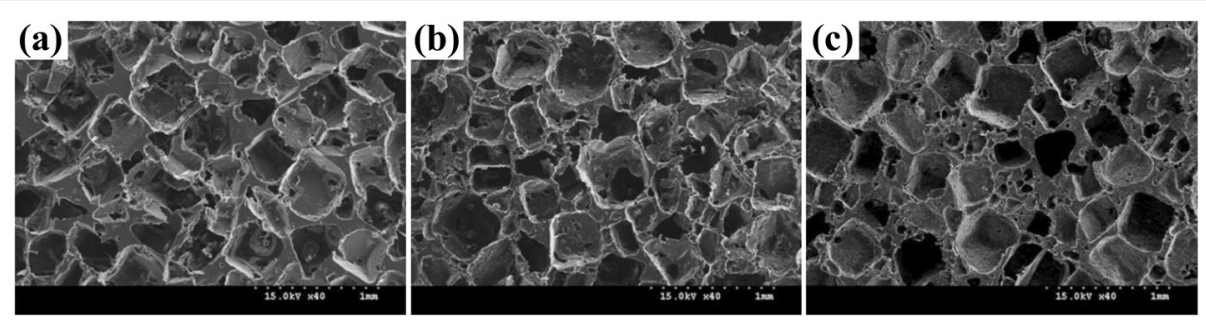

Fig. 1 Surface morphologies of the porous HDPE (a), HDPE/PEAA (b) and HDPE/PEAA/Col (c) scaffolds

enzyme-linked immunosorbent assay (ELISA). For the MTT assay, the scaffold samples were immersed in $50 \mu \mathrm{L}$ of MTT solution ( $5 \mathrm{mg} / \mathrm{mL}$ in PBS) for $4 \mathrm{~h}$. After removing the solution, the water-insoluble formazan product was dissolved in $0.04 \mathrm{~N} \mathrm{HCl}$-isopropanol in the dark. ELISA was performed using 5-bromo-2deoxyuridine (BrdU), which is incorporated during DNA synthesis in the cells. The BrdU ELISA was conducted according to the manufacturer's instructions (Roche Molecular Biochemicals, Germany). The absorbance was measured at $570 \mathrm{~nm}$, using a kinetic microplate reader $(E L \times 800$; Bio-T Instruments, Inc., Highland Park, USA).

Cell differentiation was tested by several cell staining methods, using alizarin red S, von Kossa, and alkaline phosphatase (ALP) staining. The osteoblast cells $\left(5 \times 10^{4}\right.$ cells $\left./ \mathrm{mL}\right)$ were cultured for 15 days on the three porous scaffolds and then fixed using $10 \%$ formaldehyde. For alizarin red $\mathrm{S}$ staining, the samples were treated with an alizarin red $\mathrm{S}$ solution and incubated for $20 \mathrm{~min}$. For the von Kossa assay, the fixed samples were treated with $5 \% \mathrm{AgNO}_{3}$ solution for 20 min under ultraviolet radiation, followed by the addition of $5 \% \mathrm{Na}_{2} \mathrm{~S}_{2} \mathrm{O}_{3}$ solution for $5 \mathrm{~min}$. ALP staining was done by a standard procedure according to the manufacturer's instructions (Alkaline phosphatase, Leukocyte, Procedure No. 86; Sigma-Aldrich, USA), using an alkaline dye mixture $(1 \mathrm{~mL}$ of sodium nitrate, $1 \mathrm{~mL}$ of FBB-alkaline solution, $1 \mathrm{~mL}$ of naphthol AS-BI alkaline solution, and $1 \mathrm{~mL}$ of deionized water) and a neutral red buffered solution for counterstaining [27]. The digital images of the stained cultures were obtained with a digital camera (Canon A2000 IS, Japan) and an optical microscope (Carl Zeiss, Germany).

\section{Data analysis}

The results are displayed as the mean \pm standard deviation. The statistical significance of differences between the scaffolds was determined by a Student's two-tailed $t$ test. Scheffe's method was used for multiple comparison tests at a level of $95 \%$.

\section{Results and discussion \\ Pore structure}

The surface morphology of the porous HDPE, HDPE/ PEAA, and HDPE/PEAA/Col scaffolds was observed by scanning electron microscopy. As shown in Fig. 1, interconnected pores were successfully formed in the scaffolds, and their pore sizes ranged between several microns and a few hundred microns. It is also seen that the collagen-grafted scaffold in Fig. 1(c) had slightly smaller pores than those without collagen grafting in Fig. 1(a) and (b).

The intrusion volume and porosity were measured to investigate the change of pore size by the scaffold materials and collagen grafting, and the results are shown in Table 1. The porosity of the HDPE/PEAA scaffold was similar to that of HDPE, which was approximately $65 \%$. However, when collagen was introduced to the surface of the HDPE/PEAA scaffold the porosity decreased by $5 \%$, likely due to the high molecular weight of collagen.

The pore characteristics are also key factors that affect the performance of porous scaffolds in bone reconstruction because the pore size and porosity of scaffolds affect the diffusion of nutrients and osteoblast cell attachment, migration, proliferation, and differentiation, which are vital for bone formation. Additionally, a porous surface is known to drive mechanical stability at the interface between the implant materials and the surrounding tissue [28]. Even though there is disagreement about the optimum pore size of porous scaffolds, it is generally agreed upon that the pore size and porosity play essential roles in their compatibility to cells such as osteoblasts, and pores of a few hundred microns are

Table 1 Intrusion volume and porosity of the porous HDPE, HDPE/PEAA and HDPE/PEAA/Col scaffolds

\begin{tabular}{lcc}
\hline Substrate & Intrusion volume $(\mathrm{mL} / \mathrm{g})$ & Porosity(\%) \\
\hline HDPE & 2.08 & 65.21 \\
HDPE/PEAA & 2.31 & 66.75 \\
HDPE/PEAA/Collagen & 1.88 & 59.28 \\
\hline
\end{tabular}

Standard deviation is within $10 \%$ 


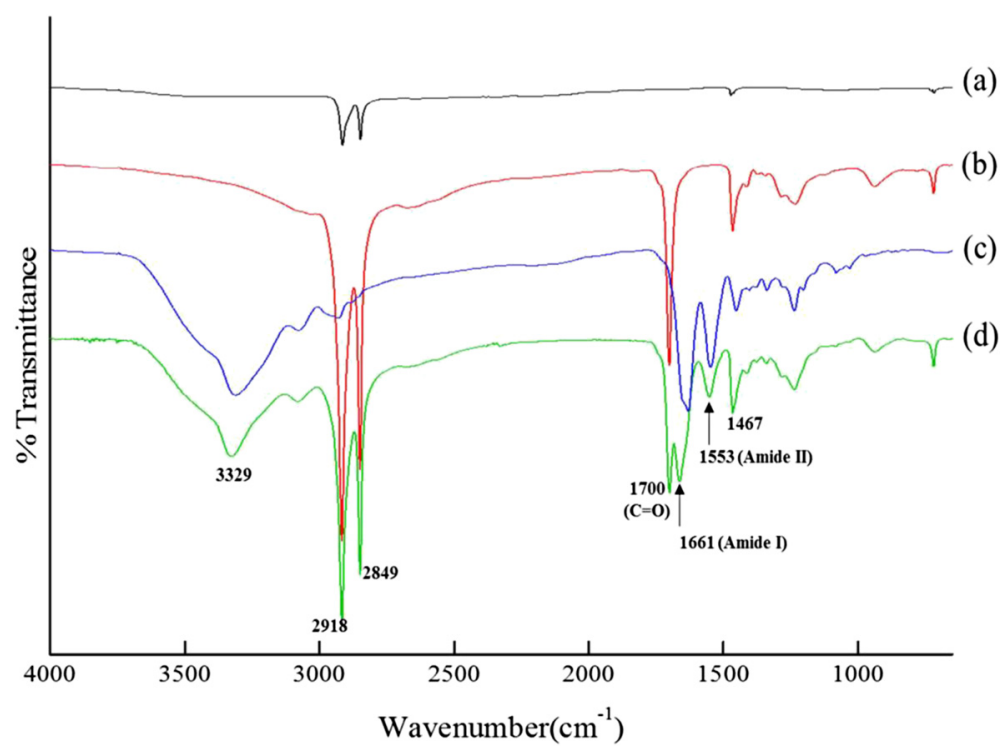

highly required $[3-5,8]$. Therefore, on the basis of the results of Fig. 1 and Table 1, it can be concluded that the pore size of the HDPE-based scaffolds prepared by the salt-leaching method is appropriate for porous bone scaffolds.

\section{Surface chemistry}

FT-IR spectra of the HDPE, HDPE/PEAA, and HDPE/PEAA/Col scaffolds and of collagen are shown in Fig. 2. Both the HDPE and HDPE/PEAA spectra exhibited bands at 2849 and $2918 \mathrm{~cm}^{-1}$, assigned to hydrocarbons $\left(\mathrm{CH}, \mathrm{CH}_{2}\right)$. For the HDPE/PEAA scaffold (Fig. 2b), the vibrational band at $1700 \mathrm{~cm}^{-1}$ based on $\mathrm{C}=\mathrm{O}$ was observed, but it did not appear for the HDPE scaffold (Fig. 2a), which proves that PEAA was well incorporated into the HDPE/PEAA scaffold. It is also seen that the HDPE/PEAA/Col scaffold (Fig. 2d) displayed the characteristic collagen peaks at 1661 and $1553 \mathrm{~cm}^{-1}$, assigned to the stretching vibration of the carbonyl group $(\mathrm{C}=\mathrm{O})$ within amide I (-CONH-) and the coupling of $\mathrm{N}-\mathrm{H}$ bending and $\mathrm{C}-\mathrm{N}$ stretching of amide II (-CONH-), respectively.

Collagen grafting on the HDPE/PEAA scaffold was further confirmed by ESCA, and the elemental compositions of the HDPE, HDPE/PEAA, and HDPE/PEAA/Col scaffolds are shown in Table 2. The atomic percentage of nitrogen was significantly increased on the surface of the HDPE/PEAA scaffold modified with L-lysine and subsequently with collagen. According to the FT-IR spectra and ESCA results, it can be confirmed that collagen grafting was successfully conducted on the porous HDPE/PEAA scaffold.

\section{Tensile properties}

Figure 3 represents the tensile strength and Young's modulus measures of the porous HDPE, HDPE/ PEAA, and HDPE/PEAA/Col scaffolds. The porous HDPE scaffold showed higher strength and modulus values, owing to the high mechanical stability of HDPE. When PEAA was incorporated into the HDPE scaffold, its Young's modulus measure decreased significantly, while the tensile strength was slightly lowered. It is also shown that grafting collagen on the scaffolds does not affect their tensile properties. PEAA is widely used as a compatibilizer for polymer blends or composites because of its functionality. Its segment of acrylic acid provides unique properties, such as polarity, crosslink ability, and adhesion to polar substrates, as well as low softening and melting points [29]. Kim et al. reported the addition of PEAA to polyethylene terephthalate/ HDPE blends, which effectively improved their

Table 2 Chemical composition of porous scaffolds calculated from their survey scan spectra

\begin{tabular}{lcccccc}
\hline Substrate & \multicolumn{6}{l}{ Atomic \% } \\
\cline { 2 - 7 } & $\mathrm{C} 1 \mathrm{~s}$ & $\mathrm{O} 1 \mathrm{~s}$ & $\mathrm{~N} 1 \mathrm{~s}$ & $\mathrm{Si} 2 \mathrm{p}$ & $\mathrm{Cl} 2 \mathrm{p}$ & $\mathrm{Na} 1 \mathrm{~s}$ \\
\hline HDPE & 93.5 & 5.3 & $<0.1$ & 1.2 & - & - \\
HDPE/PEAA & 83.2 & 11.8 & 1.0 & 2.4 & 0.3 & 0.5 \\
HDPE/PEAA/Collagen & 81.8 & 11.1 & 5.3 & 1.2 & 0.5 & 0.1 \\
\hline
\end{tabular}




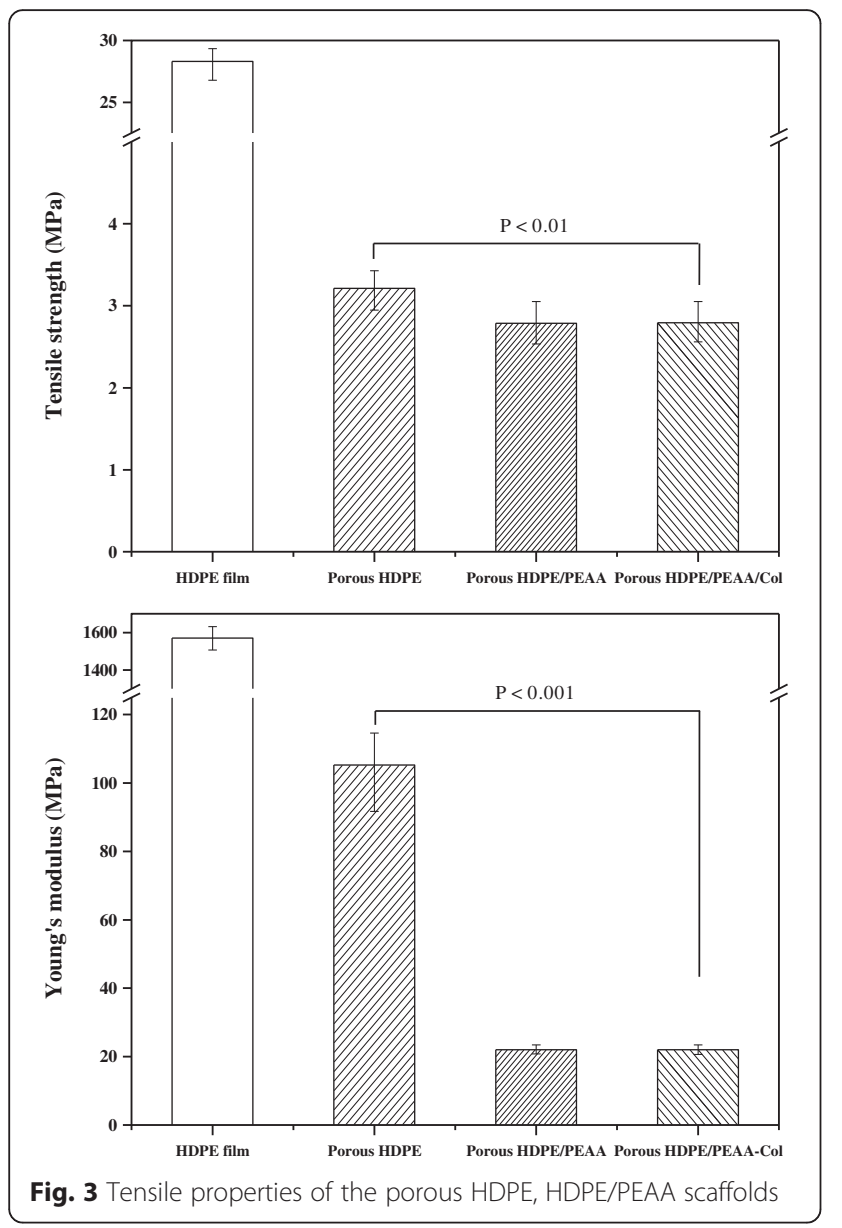

mechanical properties such as flexural yield strain and impact strength [30]. PEAA was also reported as a compatibilizer of polylactic acid/recycled lowdensity polyethylene blends, enhancing the tensile properties of the composites [31].

\section{Cell viability and proliferation}

Cell behaviors on the HDPE, HDPE/PEAA, and HDPE/ PEAA/Col scaffolds were investigated using several methods to examine their biocompatibility. First, the adhesion and cytotoxic effects of the three scaffolds were observed by using cell staining after a 1-day and 3-day incubation period. Figure 4 shows the morphologies of osteoblast cells on the surface of the scaffolds. CalceinAM, a highly lipophilic dye that can easily penetrate the cell membrane, interacts with cytosolic esterase in viable cells to result in green fluorescence. All the cells in Fig. 4 exhibited strong green fluorescence, indicating the good viability of osteoblast cells. On the porous HDPE scaffold, only a few cells had adhered, and their growth appeared to be somewhat slow (Fig. 4a and d). On the other hand, the HDPE/PEAA scaffold (Fig. 4b and e) displayed slightly better cell adhesion and cell spreading, and these properties were further enhanced when collagen was introduced to the surface of the HDPE/PEAA scaffold (Fig. 4c and f).

The nucleus and actin of the osteoblast cells cultured on the three different scaffolds were observed by double staining to examine the cytoskeleton organization. As

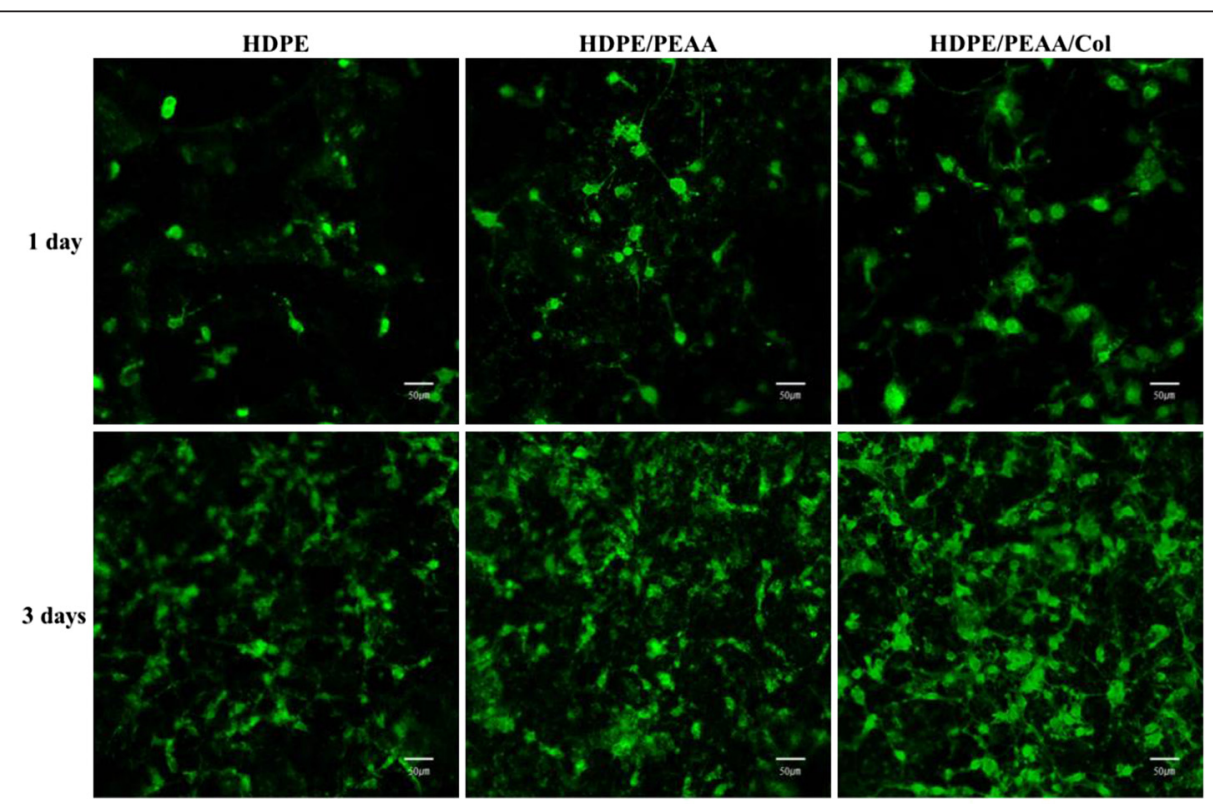

Fig. 4 Confocal laser scanning microscope images of calcein-AM dye-stained osteoblast cells cultured on the porous HDPE, HDPE/PEAA, and HDPE/PEAA/Col scaffolds 


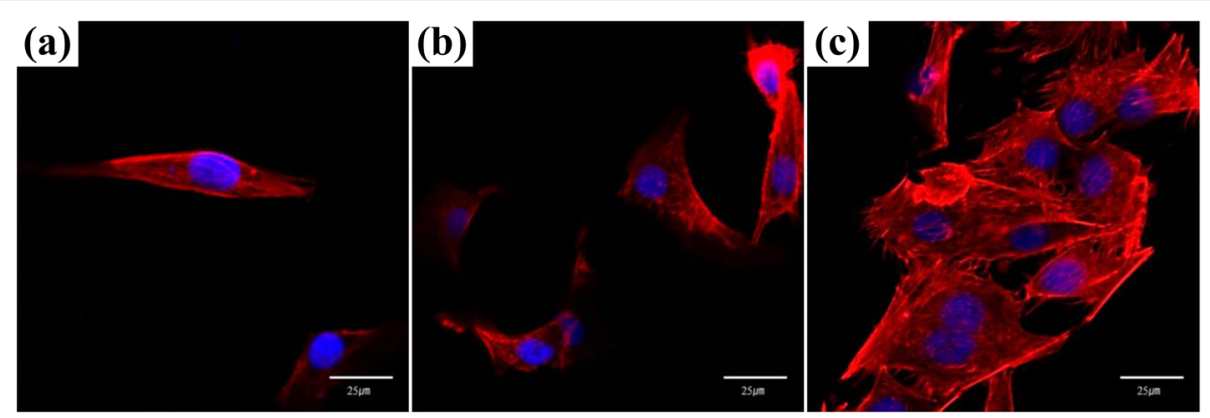

Fig. 5 Confocal laser scanning micrographs (actin in red, nucleus in blue) of osteoblast cells cultured on the porous HDPE (a), HDPE/PEAA (b), and HDPE/PEAA/Col (c) scaffolds

shown in Fig. 5, actin was stained with TRITC (red), whereas the nucleus was stained with DAPI (blue). It appeared that the cells cultured on the HDPE scaffold (Fig. 5a) expressed actin filaments slightly with a small number of cells. However, the cytoskeletons of the cells on the HDPE/PEAA scaffold (Fig. 5b) seemed more organized. The HDPE/PEAA/Col scaffold (Fig. 5c) showed a large number of cells cultured on the substrate that were clearly organized with stretched actin and stress fibers.

Figure 6 shows the MTT and BrdU assay results after a 3-day incubation of osteoblast cells on the three scaffolds. The HDPE/PEAA/Col scaffold showed significantly higher cell viability and proliferation ( $p<0.03$ for MTT and $p<0.02$ for BrdU assays) than the HDPE and HDPE/PEAA scaffolds, suggesting that collagen plays an important role in cell growth and metabolism. Not only were a large number of osteoblasts alive, but they also proliferated actively on the collagen-containing biocompatible scaffold. Collagen has been mainly used to improve biocompatibility via surface modification for biomedical applications [32-34]. It was reported that collagen grafting successfully promoted cell proliferation by cell growth and cell division on both organic and inorganic materials.

\section{Cell differentiation}

Osteoblast cell differentiation is one of the most important parameters for confirming the osteogenesis of osteoblast cells. Alizarin red S, von Kossa, and ALP staining methods have been frequently utilized to characterize the interface between calcified bone tissue and the implant surface [35-37]. For alizarin red $S$ staining, the calcification area in the cells is stained red from the formation of a calcium/alizarin red S complex. Figure 7 shows the result of alizarin red S staining of osteoblast cells on the three porous scaffolds. It can be seen that osteoblasts on the HDPE, HDPE/PEAA, and HDPE/PEAA/Col scaffold were stained in red, with the HDPE/PEAA/Col scaffold showing the most intense dark red color, resulting from accelerated cell differentiation by collagen grafting.

The von Kossa stain is also one of the ways to confirm mineralization in cell cultures by detecting

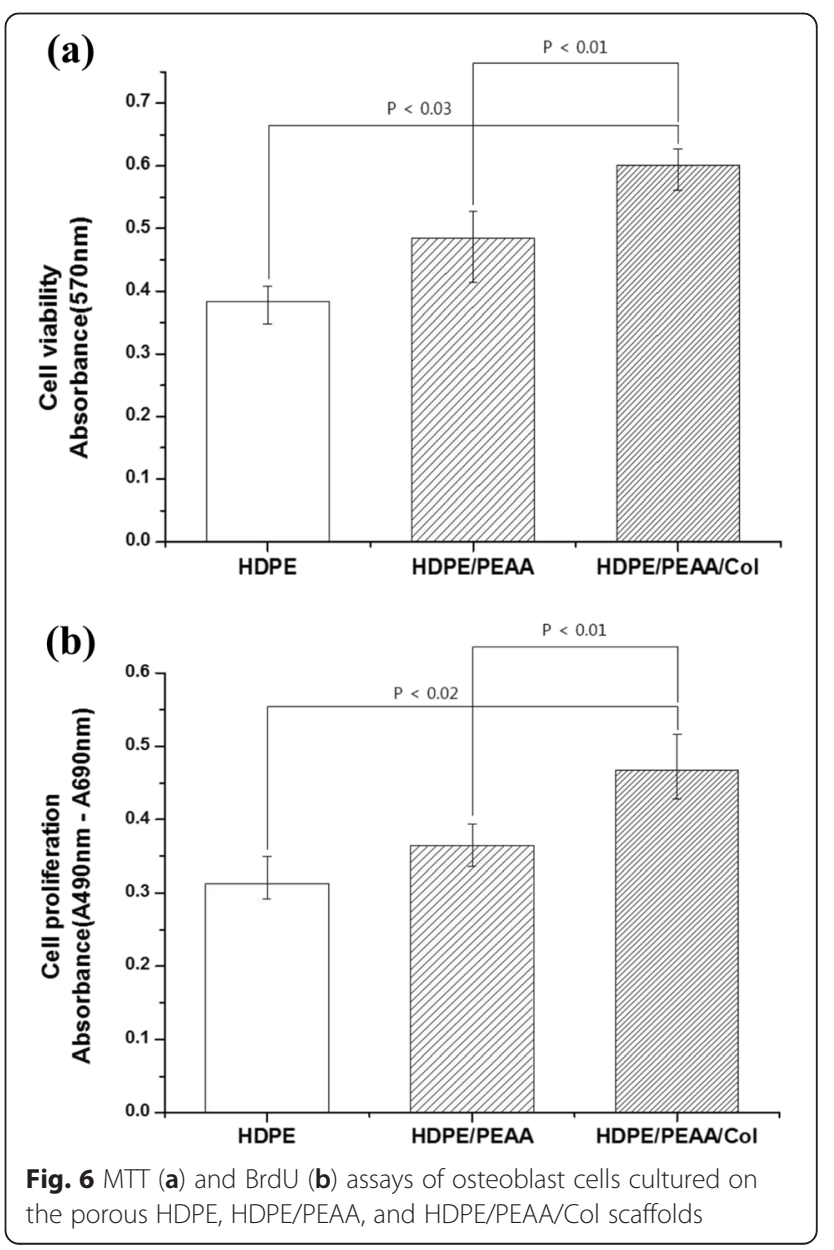




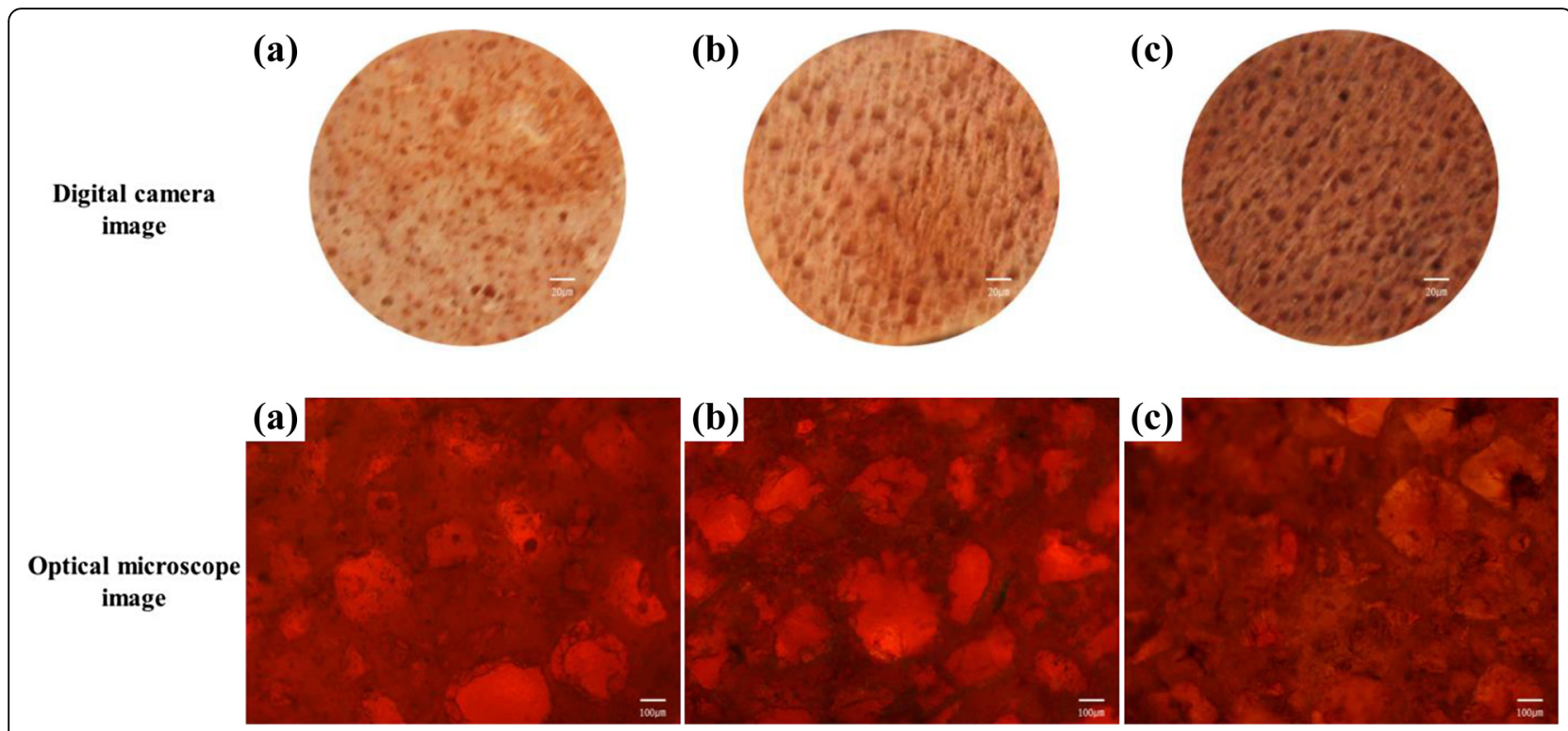

Fig. 7 Alizarin red S staining of osteoblast cells cultured on the porous HDPE (a), HDPE/PEAA (b), and HDPE/PEAA/Col (c) scaffolds

phosphate in the calcification area, which is stained as a black spot. In Fig. 8, von Kossa staining images of osteoblast cells cultured on the porous scaffolds are displayed. Osteoblast cells on the HDPE/PEAA/ Col scaffold showed the most intensive dark spots among the three scaffolds. It was therefore confirmed that collagen grafting is effective in triggering or accelerating osteoblast cell differentiation, which matches well with the alizarin red $S$ staining results in Fig. 7. The HDPE/PEAA scaffold presented better cell differentiation (Figs. $7 \mathrm{~b}$ and $8 \mathrm{~b}$ ) than the HDPE scaffold (Figs. 7a and 8a).
The differentiation of osteoblast cells was further proven by the synthesis of ALP in the cells, which appears as a blue spot (Fig. 9). ALP is an enzyme produced by osteoblast activity such as bone generation. Therefore, the amount of ALP synthesized can represent the vitality of osteoblast cells. The amount of ALP synthesized by the cells cultured on the HDPE/PEAA/Col scaffold (Fig. 9c) was higher than those on the HDPE and HDPE/PEAA scaffolds (Fig. 9a and b, respectively). Thus, the osteoblasts on the collagen-grafted scaffold had active ALP synthesis, indicating the scaffold's potential for bone generation applications.

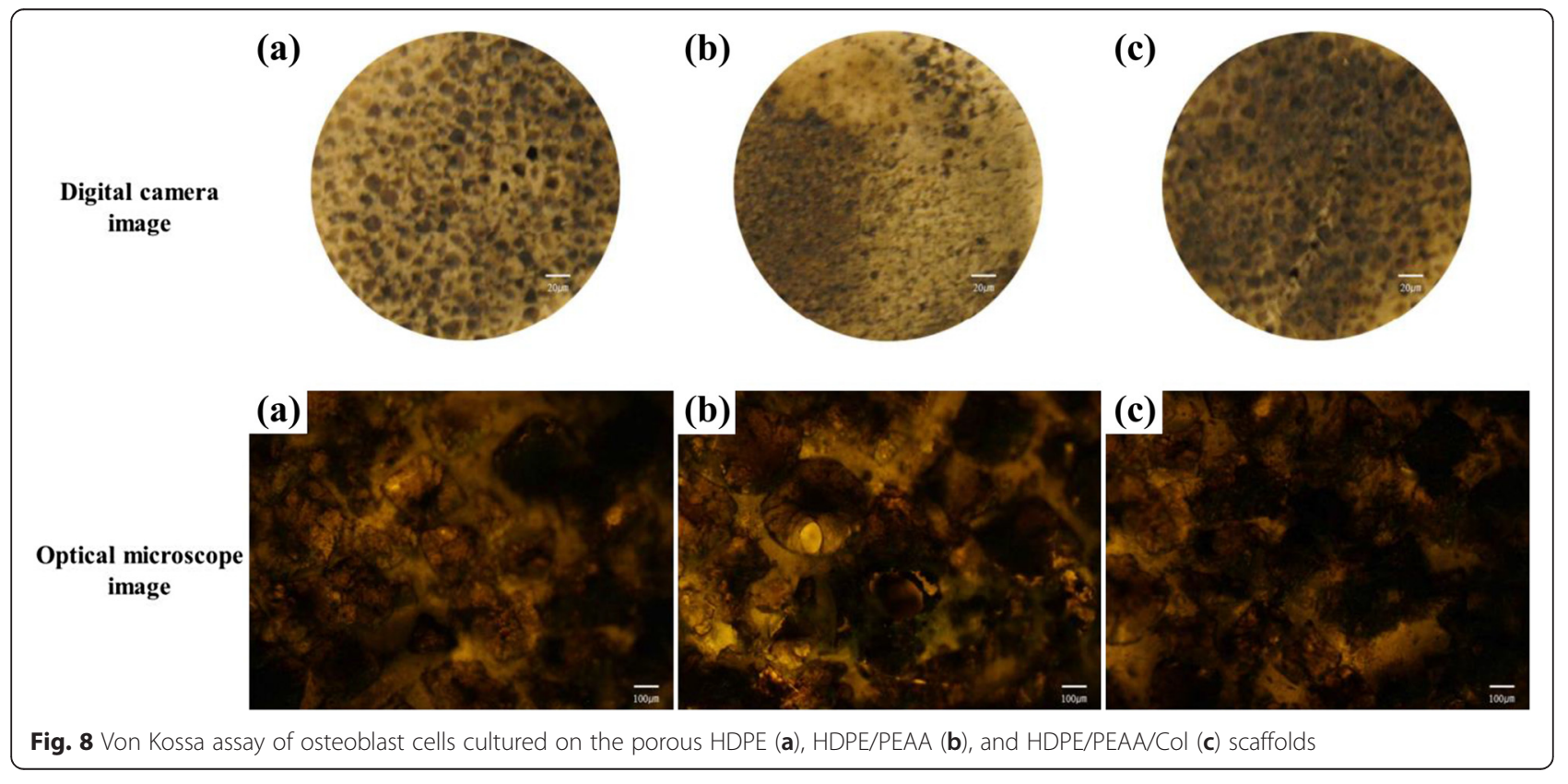



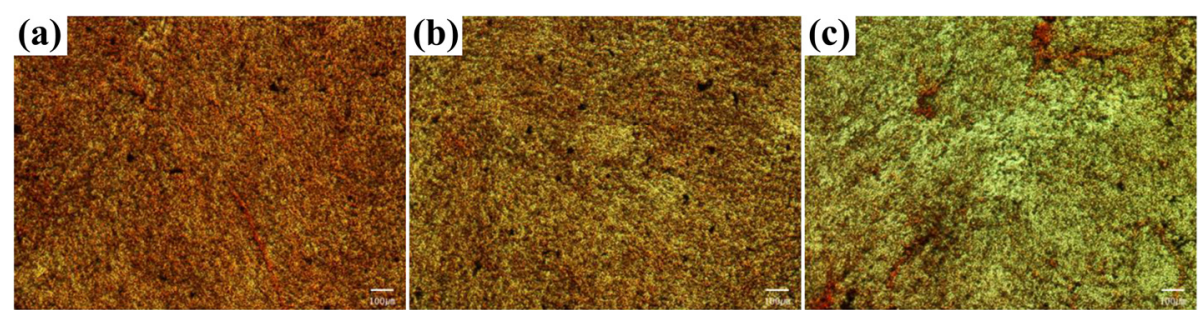

Fig. 9 ALP activity staining of osteoblast cells cultured on the porous HDPE (a), HDPE/PEAA (b), and HDPE/PEAA/Col (c) scaffolds

\section{Conclusions}

For bone reconstruction, porous scaffolds were fabricated using HDPE/PEAA composites via a saltleaching method. The surface of the porous HDPE/ PEAA scaffold was modified using collagen to enhance bone tissue compatibility. The surface modification was confirmed via FT-IR spectroscopy and ESCA by detecting the nitrogen component in collagen. It was shown that the pore size and porosity are suitable for osteoblast attachment, as confirmed by the surface images and porosity results. The cell viability and proliferation were measured by MTT and BrdU assays, with results showing that the collagen-grafted HDPE/PEAA surface is favorable for the adhesion and proliferation of osteoblast cells. Furthermore, cell differentiation was studied using several staining methods, where it was seen that osteoblasts on the collagen-grafted scaffold have outstanding differentiation. It is concluded that collagen grafting on the porous HDPE/PEAA scaffold effectively improves its biocompatibility and potential use as a bone scaffold.

\section{Acknowledgments}

This research was supported by Kyungpook National University Research Fund for the year 2013.

\section{Funding}

This research was supported by Kyungpook National University Research Fund for the year 2013.

\section{Availability of data and material}

All data are available on Journal portals in submitted manuscript. No other supporting files/data are needed along with this submission.

\section{Authors' contributions}

CSK and IKK designed the experiments. KHJ helped in writing the manuscript. HK and CBK have conceived the ideas of this study, and participated in its design. All authors read and approved the final manuscript.

\section{Competing interests}

The authors declare that they have no competing interests.

\section{Consent for publication}

The manuscript has been submitted with the consent of all authors and data of any other person not included.
Ethics approval and consent to participate

Manuscript does not include human ethics value. Hence no consent is needed.

\section{Author details}

'Department of Polymer Science and Engineering, Kyungpook National University, Daegu 702-701, South Korea. ${ }^{2}$ Department of Advanced Materials and Chemical Engineering, Catholic University of Daegu, Kyungsan, South Korea. ${ }^{3}$ Jeil Medical Corporation, Seoul, South Korea.

Received: 29 April 2016 Accepted: 19 July 2016

Published online: 27 July 2016

\section{References}

1. Imola MJ, Sciarretta V, Schramm VL. Skull base reconstruction. Curr Opin Otolaryngol Head Neck Surg. 2003;11(4):282-90.

2. Abdurrahim T, Sopyan I. Recent progress on the development of porous bioactive calcium phosphate for biomedical applications. Recent Pat Biomed Eng. 2008;1(3):213-29.

3. Mour MD, Winkler T, Hoenig E, Mielke G, Morlock MM, Schilling AF. Advances in porous biomaterials for dental and orthopaedic applications. Materials. 2010;3:2947-74.

4. Chua $C$. The design of scaffolds for use in tissue engineering. Part i. Traditional factors. Tissue Eng. 2001;7:679-89.

5. Ciara FJOB, Murphy M. Understanding the effect of mean pore size on cell activity in collagen-glycosaminoglycan scaffolds. Cell Adhes Migr. 2010;4: 377-81.

6. Anselme K. Osteoblast adhesion on biomaterials. Biomaterials. 2000;21(7): 667-81.

7. Burg KJL, Porter S, Kellam JF. Biomaterial developments for bone tissue engineering. Biomaterials. 2000;21(23):2347-59.

8. Karageorgiou V, Kaplan D. Porosity of 3D biomaterial scaffolds and osteogenesis. Biomaterials. 2005;26(27):5474-91.

9. Bose $\mathrm{S}$, Roy M, Bandyopadhyay A. Recent advances in bone tissue engineering scaffolds. Trends Biotechnol. 2012;30(10):546-54.

10. Arcos D, Vallet-Reg M. Sol-gel silica-based biomaterials and bone tissue regeneration. Acta Biomater. 2010;6(8):2874-88.

11. Baek J-Y, Xing Z-C, Kwak G, Yoon K-B, Park S-Y, Park LS, Kang I-K. Fabrication and characterization of collagen-immobilized porous phbv/ ha nanocomposite scaffolds for bone tissue engineering. J Nanomater. 2012;2012:1.

12. Lee SB, Kim YH, Chong MS, Hong SH, Lee YM. Study of gelatin-containing artificial skin v: Fabrication of gelatin scaffolds using a salt-leaching method. Biomaterials. 2005;26(14):1961-8.

13. Jin Yoon J, Ho Song S, Sung Lee D, Park TG. Immobilization of cell adhesive rgd peptide onto the surface of highly porous biodegradable polymer scaffolds fabricated by a gas foaming/salt leaching method. Biomaterials. 2004;25(25):5613-20.

14. Kim HM, Chae W-P, Chang K-W, Chun S, Kim S, Jeong Y, Kang I-K. Composite nanofiber mats consisting of hydroxyapatite and titania for biomedical applications. J Biomed Mater Res B Appl Biomater. 2010; 94B(2):380-7.

15. Ito $Y$, Hasuda H, Kamitakahara M, Ohtsuki C, Tanihara M, Kang I-K, Kwon $\mathrm{OH}$. A composite of hydroxyapatite with electrospun biodegradable nanofibers as a tissue engineering material. J Biosci Bioeng. 2005;100(1):43-9. 
16. Han I, Shim K, Kim JY, Im SU, Sung YK, Kim M, Kang I-K, Kim JC. Effect of poly(3-hydroxybutyrate-co-3-hydroxyvalerate) nanofiber matrices cocultured with hair follicular epithelial and dermal cells for biological wound dressing. Artif Organs. 2007:31(11):801-8.

17. Yoshimoto $H$, Shin $Y$, Terai $H$, Vacanti J. A biodegradable nanofiber scaffold by electrospinning and its potential for bone tissue engineering. Biomaterials. 2003;24(12):2077-82.

18. Liu JK, Gottfried ON, Cole CD, Dougherty WR, Couldwell WT. Porous polyethylene implant for cranioplasty and skull base reconstruction. Neurosurg Focus. 2004;16(3):1-5.

19. Petrie Aronin CE, Sadik KW, Lay AL, Rion DB, Tholpady SS, Ogle RC, Botchwey EA. Comparative effects of scaffold pore size, pore volume, and total void volume on cranial bone healing patterns using microspherebased scaffolds. J Biomed Mater Res A. 2009;89(3):632-41.

20. Stevens MM. Biomaterials for bone tissue engineering. Mater Today. 2008; 11(5):18-25

21. Couldwell WT, Stillerman CB, Dougherty W. Reconstruction of the skull base and cranium adjacent to sinuses with porous polyethylene implant: Preliminary report. Skull Base Surg. 1997;7(2):57.

22. James KL, Oren NG, Chad DC, William RD, William TC. Porous polyethylene implant for cranioplasty and skull base reconstruction. Neurosurg Focus. 2004;16(3):1-5.

23. Kwon JH, Kim SS, Kim B-S, Sung WJ, Lee SH, Lim JI, Jung Y, Kim S-H, Kim SH, Kim YH. Histological behavior of hdpe scaffolds fabricated by the press-andbaking method. J Bioact Compat Polym. 2005;20(4):361-76.

24. Cenzi R, Farina A, Zuccarino L, Carinci F. Clinical outcome of 285 medpor grafts used for craniofacial reconstruction. J Craniofac Surg. 2005;16(4):526-30

25. Gupta B, Plummer C, Bisson I, Frey P, Hilborn J. Plasma-induced graft polymerization of acrylic acid onto poly(ethylene terephthalate) films: Characterization and human smooth muscle cell growth on grafted films. Biomaterials. 2002;23(3):863-71.

26. Lim J-S, Kook M-S, Jung S, Park H-J, Ohk S-H, Oh H-K. Plasma treated highdensity polyethylene (hdpe) medpor implant immobilized with rhbmp-2 for improving the bone regeneration. J Nanomater. 2014;2014:7.

27. Xing Z-C, Chae W-P, Baek J-Y, Choi M-J, Jung Y, Kang I-K. In vitro assessment of antibacterial activity and cytocompatibility of silver-containing PHBV nanofibrous scaffolds for tissue engineering. Biomacromolecules. 2010;11(5): 1248-53.

28. Story BJ, Gaisser DM, Cook SD, Rust-Dawicki AM. In vivo performance of a modified csti dental implant coating. Int J Oral Maxillofac Implants. 1998; 13(6):749-57.

29. Wakabayashi K, Register RA. Micromechanical interpretation of the modulus of ethylene-(meth) acrylic acid copolymers. Polymer. 2005;46(20):8838-45.

30. Kim S, Park CE, An JH, Lee D, Kim J. The effect of functional group content on poly(ethylene terephthalate)/high density polyethylene blends compatibilized with poly(ethylene-co-acrylic acid). Polym J. 1997;29(3):274-8.

31. Syahmie Rasidi HSM, Teh PL, Ismail H. Mechanical and morphological properties of polylactic acid/recycled low density polyethylene/nypa fruticans biocomposites compatibilized with polyetylene-co-acrylic acid. Applied Mechanics and Materials. 2015;754-755:54-8.

32. Ma Z, Gao C, Gong Y, Shen J. Cartilage tissue engineering plla scaffold with surface immobilized collagen and basic fibroblast growth factor. Biomaterials. 2005:26(11):1253-9.

33. Hong Y, Gao C, Xie Y, Gong Y, Shen J. Collagen-coated polylactide microspheres as chondrocyte microcarriers. Biomaterials. 2005;26(32): 6305-13.

34. Jung K, Kang IK, Kim SM, Ahn MW, Kim SY. Immobilization of collagen on hydroxyapatite and its interaction with cells. Key Eng Mater. 2007;330:781-4.

35. Nishikawa T, Masuno K, Mori M, Tajime Y, Kakudo K, Tanaka A. Calcification at the interface between titanium implants and bone: Observation with confocal laser scanning microscopy. J Oral Implantol. 2006;32(5):211-7.

36. Cooper LF, Masuda T, Whitson SW, Yliheikkila P, Felton DA. Formation of mineralizing osteoblast cultures on machined, titanium oxide grit-blasted, and plasma-sprayed titanium surfaces. Int J Oral Maxillofac Implants. 1998; 14(1):37-47.

37. Webster TJ, Ergun C, Doremus RH, Siegel RW, Bizios R. Enhanced functions of osteoblasts on nanophase ceramics. Biomaterials. 2000; 21(17):1803-10.

\section{Submit your next manuscript to BioMed Central and we will help you at every step:}

- We accept pre-submission inquiries

- Our selector tool helps you to find the most relevant journal

- We provide round the clock customer support

- Convenient online submission

- Thorough peer review

- Inclusion in PubMed and all major indexing services

- Maximum visibility for your research

Submit your manuscript at www.biomedcentral.com/submit
Biomed Central 